\title{
SIMULATION OPTIMIZATION APPLIED TO INJECTION MOLDING
}

\author{
María G. Villarreal \\ Rachmat Mulyana \\ José M. Castro \\ Dept. of Industrial, Welding and Systems Engineering \\ The Ohio State University \\ 1971 Neil Avenue, Columbus, OH 43210, USA
}

\author{
Mauricio Cabrera-Ríos
}

Industrial Engineering Department

University of Puerto Rico at Mayagüez

PO Box 9043, Mayagüez, PR, 00681, USA

\begin{abstract}
In this work, a simulation optimization method developed by Villarreal and Cabrera-Ríos (2007) is applied to injection molding. The method uses design of experiments and adaptive metamodeling techniques. The application of the method to several global optimization test functions as well as non linear polynomial and non polynomial functions point towards a quick convergence to highly attractive solutions with a low number of simulations. Here the method is used to select the best processing conditions for injection molding a simple rectangular plaque and a real automotive part using different performance criteria.
\end{abstract}

\section{INTRODUCTION}

The use of simulation for determining injection molding processing conditions has been the subject of much research in the past (Smith, Tortorelli, and Tucker 1998; Gokce, Hsiao, and Advani 2002; Alam and Kamal 2005). Most researchers, in this area, commonly have strong physics and chemistry background but are not specialists in optimization. For this reason, the common use of simulation models has consisted in the evaluation of limited combinations of processing conditions from which one is finally selected. This practice is consistent with process improvement. On the other hand, optimization consists of finding the best possible processing conditions in terms of specific performance measures. Simulation Optimization is formally the area that deals with the optimization of simulation models. The aim of a simulation optimization method is, to provide a structure to determine the values of the controllable variables that optimize an objective function defined as a combination of the simulation model's outputs (Swiseher et al. 2000). An optimization routine uses the calculated values of the objective function and previous evaluations, to select a new set of input values, this is continued until a pre-selected convergence criteria is satisfied (April et al. 2004). Figure 1 shows a schematic diagram of this process.

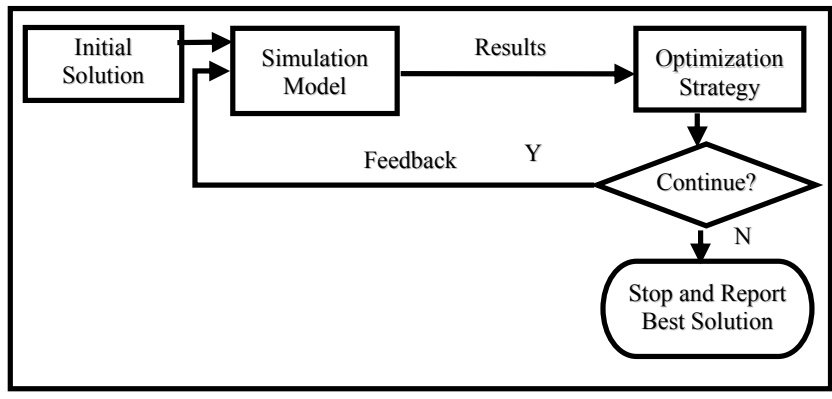

Figure 1: Simulation-Optimization scheme.

The general formulation of the optimization problem of interest is as follows:

$$
\begin{array}{cc}
\text { Minimize } & f(\mathbf{x}) \\
\text { Subject to } \quad \boldsymbol{h}(\mathbf{x})=0 \\
\boldsymbol{g}(\mathbf{x}) \leq 0 \\
\mathbf{x}_{l} \leq \mathbf{x} \leq \mathbf{x}_{\boldsymbol{u}}
\end{array}
$$

where $\mathbf{x}=\left(x_{1}, x_{2}, \ldots, x_{v}\right)$ is a vector containing the values of the $v$ simulation controllable variables to be found subjected to equality and/or inequality constraints $(\boldsymbol{h}(\mathbf{x}), \boldsymbol{g}(\mathbf{x}))$, lower and upper bounds, $\mathbf{x}_{l}$ and $\mathbf{x}_{\boldsymbol{u}}$, aiming to minimize the expected value of an objective function $f(\mathbf{x})$ across multiple replicates.

Classical mathematical optimization methods' requirement to have explicit equations as objective functions and constraints limit their direct applicability in simulation models. A cure in this case has been provided by the areas of design of experiments and metamodeling: the creation of statistical prediction models based on a limited number of measurements i.e. metamodels. These measurements can take the form of the outputs of a simulation model. The key in this last case is on selecting a number of samples that are statistically representative to provide the right basis to build the metamodels. Requiring a large number of these 


\section{Villarreal, Mulyana, Castro, and Cabrera-Ríos}

samples would imply running an impractically large number of simulations. This would be especially impractical in finite element simulations that take long times to run, such as injection molding large and complicated parts, requiring fine meshes. On the other hand, the samples should be representative enough to provide significant knowledge to the models.

There are a number of simulation-optimization methods (SOM) in the literature. Of particular interest to this work is the use of metamodels. A comprehensive review of metamodeling techniques can be found in (Barton 1998). Linear regression methods certainly appear to be the most widely used. More recently, however, artificial neural networks (ANNs) seem to be gaining popularity also (April et al. 2003). The large number of works related to simulationbased metamodels (Andradóttir 1998; Azadivar 1999; Swisher et al. 2000; Fu 2001; Ólafsson and Kim 2002; Fu, Glover, and April 2005), and our own work on the optimization of physical and chemical phenomena (Cabrera-Ríos, Castro, and Mount-Campbell 2002; Cabrera- Ríos et al. 2002a; Castro, Cabrera-Ríos and Mount-Campbell 2004; Castro et al. 2005; Castro et al. 2006), guided our decision to make metamodeling the focus of the SOM proposed in Villarreal (2007). In this work, it is shown how this SOM can greatly enhance the capability to select injection molding processing and design parameters to optimize selected objective functions using flow simulation.

\section{SIMULATION OPTIMIZATION PROPOSED METHOD}

The method used in this work includes design of experiments (DOE) and metamodeling techniques as schematically shown in Figure 2. The method starts with an initial design of experiments from which an incumbent solution is obtained. At each iteration, a metamodel is obtained using the available set of points and is used to generate a new attractive point where a simulation is performed. The simulated value of the new point is compared against the incumbent for updating purposes. A series of stopping criteria are evaluated and, if none is met, the new point is added to the existing set of points and a new iteration begins. Otherwise, the method stops.

Referring to Figure 2, the method proposed for optimization problems with a single criterion represented in formulation (1) is as follows:

\section{Initialization}

1. Initial DOE: The method begins with a DOE. The DOE will consist on $n$ runs containing combinations of the $v$ controllable variables $\mathbf{x}^{\mathrm{i}}=\left(x_{1}, x_{2}, x_{3}, \ldots, x_{v}\right)^{\mathrm{i}}$ of interest, as well as their evaluations $f\left(\mathbf{x}^{\mathrm{i}}\right)$, where $\mathrm{i}=1,2, \ldots, n$. If a replicated DOE is used, the value of $f\left(\mathbf{x}^{\mathrm{i}}\right)$ will be the average across the replicates. A Central Composite or a D-Optimal Design have been experimentally shown to be suited for this purpose. Current research is geared towards providing more precise DOE selection rules.

2. Select incumbent: Considering the optimization criterion detailed in formulation (1), the DOE run with the minimum objective value is selected as the current best solution or incumbent, $\left[\mathbf{x}_{k \text {-best }}, f\left(\mathbf{x}_{k \text {-best }}\right)\right]$. Also, an iteration counter is initialized in this step, $k:=0$.

\section{Main Iteration}

3. Update counter: $(k=k+1)$

4. Obtain metamodel: Using the available points, build the $k$-th metamodel, $\hat{f}(\cdot)_{k}$. In case of having only few variables, a saturated metamodel is used i.e. one that uses all available degrees of freedom, in this case a regression model with $(n-1)+(k-1)$ coefficients.

5. Optimize metamodel: Using the metamodel as objective function to be minimized subjected to side restrictions, a multiple starting points heuristic is used along with a local optimizer to obtain an attractive solution, $\mathbf{x}_{k}$.

6. Simulate the new point: Estimate, via simulation, the value of $f\left(\mathbf{x}_{k}\right)$ considering that if a replicated DOE was used, the same number of replicates is used for the new point and the mean value across them is reported.

7. Evaluate if the new point is better than the incumbent: In this case, evaluate if $\mathbf{x}_{k}$ has an objective value strictly lower than $\mathbf{x}_{(k-1) \text {-best }}$ i.e. if $\quad f\left(\mathbf{x}_{k}\right)$ $<f\left(\mathbf{x}_{(k-1) \text {-best }}\right)$.

8. Update the incumbent: Update the incumbent according to the evaluation in the previous step. If $f\left(\mathbf{x}_{k}\right)<f\left(\mathbf{x}_{(k-1) \text {-best }}\right)$, then the following is set $\quad\left[\mathbf{x}_{k-}\right.$ best,$\left.f\left(\mathbf{x}_{k \text {-best }}\right)\right]:=\left[\mathbf{x}_{k}, f\left(\mathbf{x}_{k}\right)\right]$, otherwise, the incumbent remains the same.

9. Evaluate the stopping criteria: In this work, the following criteria were used: stop if (1) $\mathbf{x}_{k}$ belongs to the initial DOE or is similar to any of the points generated on previous iterations; (2) if the coefficient of determination, $R^{2} \geq \varepsilon$; (3) the maximum number of iterations has been reached.

If any of the stopping criteria is met, the method stops and the incumbent is reported as the final output. Otherwise, then $\mathbf{x}_{k}$ is added to the set of points available to build a new metamodel, and the main iteration is repeated. 
Villarreal, Mulyana, Castro, and Cabrera-Ríos

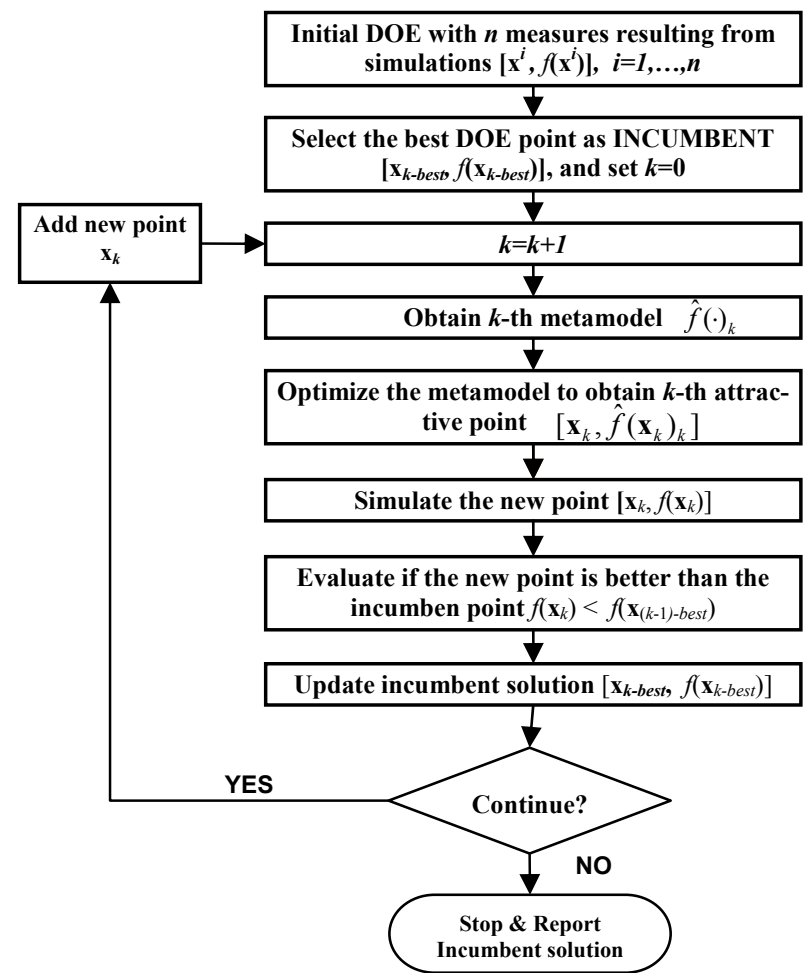

Figure 2: Simulation Optimization Proposed Method.

The traditional basic idea in metamodeling-based optimization is that a good approximation is necessary to provide a good optimization sequence. In fact, in many algorithms, the aim is to obtain a metamodel that provides a competitive global approximation. The method outlined here differs from the traditional approach in two ways: (1) at each iteration it uses all available information to build a metamodel that uses all degrees of freedom, and (2) as information is added through the progressive iterations of the method, it aims for a local fit. The observed results are that, by purposefully building overfitted metamodels, many real local minima are avoided. These observations are supported by the results presented in the next section, where the method is evaluated using several global optimization test functions as well as non linear polynomial and non polynomial functions.

\section{EVALUATION OF THE METHOD}

Two evaluation scenarios have been used thus far for the proposed method: (1) the optimization of seven known test functions for global optimization, (2) several Artificial Neural Networks (ANNs). The performance of the method is reported assuming that a simulation run is performed every time it is necessary to evaluate the objective function at a particular point.

\subsection{Test Functions for Global Optimization}

Seven test functions for unrestricted global optimization were used to evaluate the proposed method: 1) Sphere, 2) Rosenbrock, 3) Rastringin, 4) Griewank, 5) GoldsteinPrice, 6) Easom, and 7) Schwefel. Functions 1, 2 and 6 are unimodal, and the rest are multimodal. Function 6 has the added difficulty of having a large valley. All functions are considered in a 2-dimensional space. Functions 1 and 4 were also considered in a 9-dimensional space. Table 1 shows the number of simulations (objective function evaluations) performed under the proposed method until a stopping criterion was met; the objective value found follows to the right, as well as the optimal value and the order of magnitude of the range of the objective function in the sampled space. Rows 2 thru 8 show the results for the seven functions in 2 dimensions, and the last two rows the results for the functions in 9 dimensions. Figure 3 shows the Goldstein-Price function as well as the final metamodel.

Table 1: Evaluation using the test functions

\begin{tabular}{|l|c|c|c|c|}
\hline Function & $\begin{array}{c}\text { Number of } \\
\text { Simulations }\end{array}$ & $\begin{array}{c}\text { Best Value } \\
\text { Found }\end{array}$ & $\begin{array}{c}\text { Targeted Optimal } \\
\text { Value }\end{array}$ & $\begin{array}{c}\text { Order of } \\
\text { Magnitude of the } \\
\text { response range }\end{array}$ \\
\hline Sphere & 10 & 0 & 0 & $10^{1}$ \\
\hline Rosenbrock & 13 & 0 & 0 & $10^{4}$ \\
\hline Rastringin & 9 & 0 & 0 & $10^{1}$ \\
\hline Griewank & 9 & 0 & 0 & $10^{0}$ \\
\hline $\begin{array}{l}\text { Goldstein- } \\
\text { Price }\end{array}$ & 15 & 3 & 3 & $10^{5}$ \\
\hline Easom & 10 & 0 & -1 & $10^{0}$ \\
\hline Schwefel & 19 & 464.78 & 0 & $10^{3}$ \\
\hline Sphere & 74 & 0 & 0 & $10^{2}$ \\
\hline Griewank & 74 & 0.16 & 0 & $10^{1}$ \\
\hline
\end{tabular}
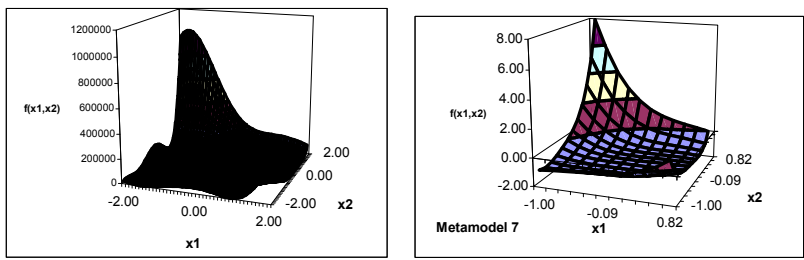

Figure 3: Goldstein-Price function (left) and final metamodel found with the proposed method (right).

Referring to Table 1, the proposed method found the optimal solution in six cases. It also found values very close to optimal in two cases, and failed to find an attractive solution only in one case, the Schwefel function. The results, then, are very promising in terms of solution quality considering the difficulty of these functions and the low probability of finding an objective function in simulation of actual manufacturing cases that resembles the Schwefel test function. Furthermore, the final solutions were found with a modest number of simulation runs.

\subsection{Artificial Neural Networks}


Some specific ANN architectures are known to be universal nonlinear approximators. For this reason, it was decided to use ANNs to generate nonlinear objective functions. In particular, feedforward multilayer ANNs with $v=2$ neurons in the input layer (number of controllable variables), 2 and 3 neurons in the hidden layer $(m)$ and one neuron in the output layer (the objective value prediction). Table 2 contains the result of this evaluation. The targeted best known solution (last column of Table 2) was determined by evaluating 121 solutions in a factorial grid for two variables and 1331 solutions in a factorial grid for three variables. In the cases involving the ANNs, the proposed method found solutions very close to the best known solution using a low number of simulations.

Table 2: Evaluation using ANNs

\begin{tabular}{|c|c|c|c|}
\hline ANN(v, $\boldsymbol{m , 1})$ & $\begin{array}{c}\text { Number of } \\
\text { Simulation } \\
\text { Runs }\end{array}$ & $\begin{array}{c}\text { Best Objective } \\
\text { Value Found }\end{array}$ & $\begin{array}{c}\text { Targeted Best } \\
\text { Known Solution }\end{array}$ \\
\hline RNA(2,3,1) & 16 & -1.23 & -1.30 \\
\hline RNA(2,3,1) & 13 & -0.41 & -0.58 \\
\hline RNA(2,3,1) & 13 & -0.34 & -0.43 \\
\hline RNA(2,3,1) & 13 & -1.44 & -1.47 \\
\hline RNA(2,3,1) & 10 & -0.97 & -1.09 \\
\hline RNA(3,3,1) & 23 & -2.52 & -2.63 \\
\hline RNA(3,3,1) & 24 & -2.14 & -2.18 \\
\hline
\end{tabular}

In this section we have shown that the proposed method does a good job finding if not the best, close to the best value for known test functions, in the next two sections we apply the method to injection molding. First to a simple flat plate representative of the molds in our lab and secondly to a real automotive part molded by one of our industrial sponsors.

\section{INJECTION MOLDING APPLICATIONS}

Injection Molding (IM) is considered to be one of the most important processes in the manufacturing of plastic parts. One of the main advantages of IM is that parts can be manufactured economically with little or virtually no finishing operations (Rosato and Roseto 1986). Today, more than one-third of all the thermoplastic materials are injection molded and more than half of all the polymer processing equipment is for IM (Oswald and HernandezOrtiz 2006).

During IM, processing conditions such as melt temperature, mold temperature, pack/hold pressure and duration, and cooling time have to be properly set to ensure the quality of the molded components. Often, these conditions are set by process engineers based on prior experience, resin supplier's recommendations, and/or reference handbooks. These conditions are usually further adjusted by trial and error on the shop floor. This approach is highly dependent on the experience of molding operators and can be costly and time consuming, especially with a new resin and/or new application (Zhou and Turng 2007).

With recent advances in numerical modeling and computer simulation techniques, a large effort has been made in developing computer simulation tools to improve and facilitate the modeling of the injection molding process (Zhou and Turng 2007). IM simulations are a very cost effective way of evaluating expensive new molds before they are built (Gaido 2007).

In this work the simulation software package MoldFlow Plastic Insight (MPI) was used to analyze the molding of a rectangular plate as well as a real automotive part. MPI allows the user to input a computer aided design (CAD) drawing of the part to be molded, in order to evaluate the effect of processing and or injection locations on part quality and cycle time.

A critical decision in IM is the location of the injection gate, which needs to be decided before the mold is made. While processing variables can be adjusted during start up, changing the gate location at a later stage involves great cost. The effect of gate location on process consistency for an automotive part was analyzed in (Gaido et al. 2007) using a multicriteria optimization method called Data Envelopment Analysis (DEA). The injection gate location must be decided while keeping in mind important criteria such as having low variability around critical performance measures.

In any manufacturing process such as IM, it is not realistic to assume that the process variables will always be at the intended set points. The process settings can vary significantly making it important to replicate this scenario in the problem under analysis. For example, when the mold temperature $\left(\mathrm{T}_{w}\right)$ is set to $100^{\circ} \mathrm{C}$ in the real IM production, factors such as ambient temperature and process cycles can cause the temperature of the mold to vary, say, up to $110^{\circ} \mathrm{C}$. This leads to variability in the process and it turn, to variability in the performance measures. It is critical to minimize this variability in order to have a more consistent process. As a matter of fact, in most cases, minimizing variability of the performance measures is as important if not, more important than the actual values of the performance measures.

When using a simulations, the output will always be the same at a specific combination of process settings; therefore it is necessary to introduce variability in an explicit manner to replicate the real process. Gaido (2007) introduced variability in the analysis by adding small perturbations to the nominal set points. For example, if is necessary to simulate a process with $\mathrm{T}_{w}$ set at $100^{\circ} \mathrm{C}$ with a variability of $\pm 10^{\circ} \mathrm{C}$, simulations were performed at $90^{\circ} \mathrm{C}$, $100^{\circ} \mathrm{C}, 110^{\circ} \mathrm{C}$ and the average of the performance measure values was assigned to the nominal set point of $100^{\circ} \mathrm{C}$. This method of introducing variability is useful when the combinations of runs are not numerous. Additional alternatives to introducing variability into IM simulations were presented in Castro (2005). 
In this work, the selection of the injection locations for an automotive part in order to minimize the variability around a key performance measure is approached as an optimization problem using the SOM described in Section 2.

\subsection{Simple Rectangular Plaque}

To better illustrate the use of the method, in this section we show the application of the proposed SOM using a simple part, representative of the molds available in our labs. Consider the part shown in Figure 4. The rectangular plaque is to be injection molded through a fan gate. The dimensions of the plaque are $0.12 \mathrm{~m} \times 0.06 \mathrm{~m} \times 0.03 \mathrm{~m}$. The material was Dow chemical USA Styron 615 APR (Poly-styrene).

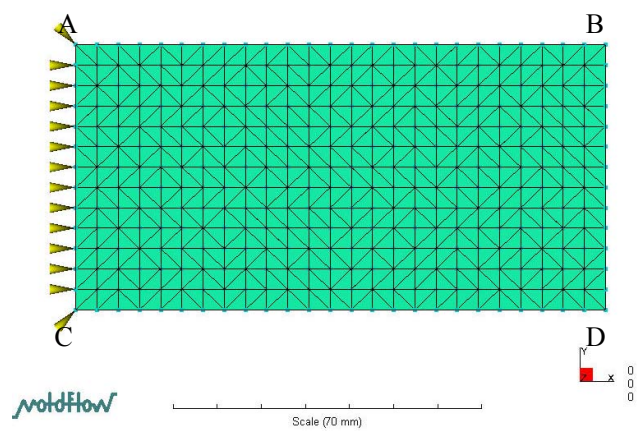

Figure 4: Rectangular plaque to be injection molded

Here we show as performance measures cycle time and part shrinkage. Shrinkage was measured on the four edges of the part: AB, BC, CD and DA. Modeling results showed that these performance measures were functions of mainly two controllable variables: Melt Temperature $\left(T_{m}\right)$ and Packing pressure $\left(P_{p}\right)$. These were varied in the ranges $[176,260]{ }^{\circ} \mathrm{C}$ and $[40,80] \mathrm{MPa}$ respectively using Moldflow $^{\mathrm{TM}}$.

Table 4: Several optimization cases approached with the proposed method

\begin{tabular}{|c|c|c|c|c|}
\hline $\begin{array}{l}\text { Performance Measure } \\
\text { (minimize) }\end{array}$ & $\begin{array}{l}\text { Number of } \\
\text { Simulations }\end{array}$ & $\begin{array}{l}\text { Best Solutions Found } \\
\left(T_{m}{ }^{\circ} \mathrm{C}, P_{p} \mathrm{MPa}\right)\end{array}$ & $\begin{array}{l}\text { Best Value Found } \\
\quad \mathrm{E}\left[f\left(T_{m}, P_{p}\right)\right]\end{array}$ & $\mathbf{R}^{2}$ \\
\hline Cycle time (CT) & 10 & $\begin{array}{l}(176,40) \\
(176,60) \\
(176,80)\end{array}$ & $\mathrm{CT}=14.68 \mathrm{sec}$ & 1.000 \\
\hline $\begin{array}{l}\text { Absolute Shrinkage Difference between } \\
\text { edges DA and BC (AS) }\end{array}$ & 11 & $(176,40)$ & $|\mathrm{DA}-\mathrm{BC}|=0.01 \mathrm{~mm}$ & 0.9997 \\
\hline Total Absolute Shrinkage (TAS) & 17 & $\begin{array}{l}(188,79) \\
(189,80) \\
\end{array}$ & $\mathrm{TAS}=0.22 \mathrm{~mm}$ & 1.000 \\
\hline $0.5 \mathrm{CT}+0.5 \mathrm{AS}$ & 9 & $(176,40)$ & $\begin{array}{l}\mathrm{CT}=14.68 \mathrm{sec} \\
|\mathrm{DA}-\mathrm{BC}|=0.01 \mathrm{~mm}\end{array}$ & 0.9993 \\
\hline $0.5 \mathrm{TC}+0.5 \mathrm{TAS}$ & 9 & $(176,80)$ & $\begin{array}{l}\mathrm{CT}=14.68 \mathrm{sec} \\
\mathrm{TSA}=0.32 \mathrm{~mm}\end{array}$ & 0.9994 \\
\hline $0.5 \mathrm{AS}+0.5 \mathrm{TAS}$ & 9 & $(176,40)$ & $\begin{array}{l}\mathrm{AS}=0.01 \mathrm{~mm} \\
|\mathrm{DA}-\mathrm{BC}|=0.79 \mathrm{~mm}\end{array}$ & 0.9994 \\
\hline $1 / 3 \mathrm{TC}+1 / 3 \mathrm{AS}+1 / 3 \mathrm{TAS}$ & 9 & $(176,40)$ & $\begin{array}{l}\mathrm{TC}=14.68 \mathrm{sec} \\
|\mathrm{DA}-\mathrm{BC}|=0.01 \mathrm{~mm} \\
\mathrm{TAS}=0.79 \mathrm{~mm}\end{array}$ & 0.9995 \\
\hline
\end{tabular}

Several cases were defined as optimization problems to be solved using the proposed method. It was decided to start with a central composite design as shown in Table 3 .

Table 3: Initial Design of Experiments

\begin{tabular}{|c|c|c|c|c|c|c|c|c|}
\hline \multirow[b]{2}{*}{$\Xi$} & \multirow[b]{2}{*}{$\begin{array}{c}T_{m} \\
\left({ }^{\circ} \mathbf{C}\right)\end{array}$} & \multirow[b]{2}{*}{$\begin{array}{c}\boldsymbol{P}_{p} \\
(\mathbf{M P a})\end{array}$} & \multicolumn{4}{|c|}{ Absolute Shrinkage (mm) } & \multirow{2}{*}{$\begin{array}{c}\text { Total } \\
\text { Absolute } \\
\text { Shrinkage } \\
\mathrm{E}\left[f\left(T_{m}, P_{p}\right)\right] \\
(\mathrm{mm})\end{array}$} & \multirow{2}{*}{$\begin{array}{l}\text { Cycle } \\
\text { time } \\
(\mathrm{sec})\end{array}$} \\
\hline & & & $\mathbf{A B}$ & BC & CD & DA & & \\
\hline 1 & 176 & 40 & 0.23 & 0.16 & 0.23 & 0.17 & 0.79 & 14.68 \\
\hline 2 & 176 & 80 & 0.06 & 0.03 & 0.06 & 0.17 & 0.32 & 14.68 \\
\hline 3 & 197 & 60 & 0.12 & 0.04 & 0.12 & 0.19 & 0.47 & 16.18 \\
\hline 4 & 218 & 50 & 0.23 & 0.08 & 0.23 & 0.20 & 0.74 & 17.68 \\
\hline 5 & 218 & 60 & 0.21 & 0.07 & 0.21 & 0.19 & 0.68 & 17.68 \\
\hline 6 & 218 & 70 & 0.20 & 0.06 & 0.20 & 0.19 & 0.65 & 17.68 \\
\hline 7 & 239 & 60 & 0.30 & 0.15 & 0.30 & 0.21 & 0.96 & 18.67 \\
\hline 8 & 260 & 40 & 0.35 & 0.18 & 0.35 & 0.12 & 1.00 & 19.67 \\
\hline 9 & 260 & 80 & 0.38 & 0.20 & 0.38 & 0.22 & 1.18 & 19.67 \\
\hline
\end{tabular}

As example applications of the method, several cases shown in table 4, were selected. Among them, to minimize the total absolute shrinkage, defined as the sum of the absolute values of shrinkage measured in edges $\mathrm{AB}$ thru $\mathrm{DA}$, minimize cycle time alone, as well as the optimization of different weighted composite objective functions. When using the weighted functions, special care was given to scaling all performance measures to fall within -1 and 1 . Their results are shown in Table 4.

The results demonstrate, that with little effort in terms of the number of simulations, we can find attractive processing conditions to the different cases evaluated. 


\subsection{A Real Automotive Part}

\subsubsection{Problem Description}

This study aims to select the best injection gates configuration from three different injection scenarios, as well as the values of mold temperature $\left(\mathrm{T}_{w}\right)$ and melt temperature $\left(\mathrm{T}_{m}\right)$ for an automotive part in order to minimize variability in a key performance measure.

The part studied in this case is the Honda Civic bumper, which can be seen in Figure 5.

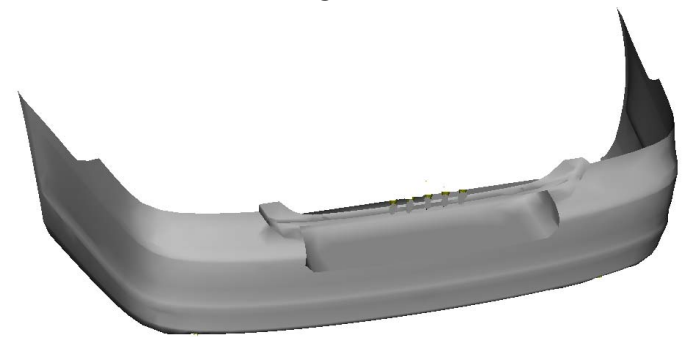

Figure 5: Honda Bumper under analysis

The bumper is injection molded using Thermoplastic Polyopefin (TPO) D17133 manufactured by SOLVAY. The fill time was kept constant at $12 \mathrm{sec}$. For simplicity in the analysis, the overall thickness of the bumper was kept constant at $3 \mathrm{~mm}$. with a total volume of $4066.45 \mathrm{~cm}^{3}$. The packing pressure was held constant at $70 \mathrm{MPa}$. $\mathrm{T}_{w}$ was varied in the range $[25,95]^{\circ} \mathrm{C}$ and $\mathrm{T}_{m}$ in $[200,260]^{\circ} \mathrm{C}$. The three different injection scenarios are shown in Figure 6. The individual points that are located on each side of the mold represent point source gates and the central group of points represent a single fan gate. In Figure 6: i) represents injection from the top; ii) injection from the bottom and iii) an alternating injection location with the fan gate at the top and the point sources located at the bottom of the mold. Each of these cases were selected based on the recommendations from Honda of America Manufacturing.

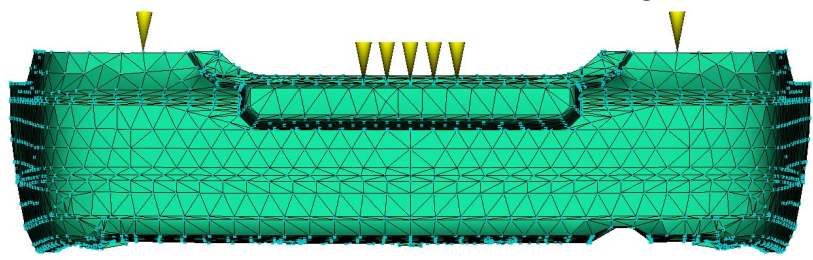

(i) Injection Top

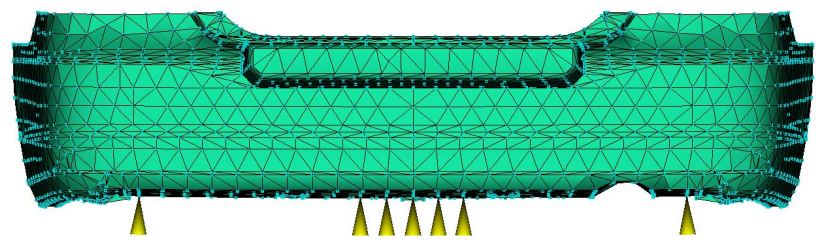

(ii) Injection Bottom

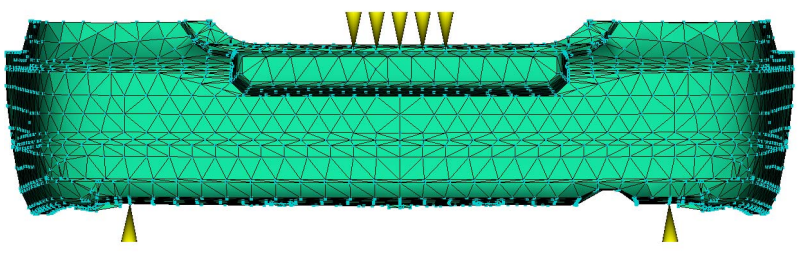

(iii) Alternate injection

Figure 6: Injection locations evaluated

A quality indicator used, to follow part quality during actual manufacturing is the shrink line shown in Figure 7, which we will refer to line $A$. The shrinkage was then defined as the absolute difference between the designed length of the line and its length after injection. The absolute value of the shrinkage if consistent, can be accounted by mold design, thus minimizing the variability around this key performance measure to provide a consistent process became the natural selection for the optimization task.

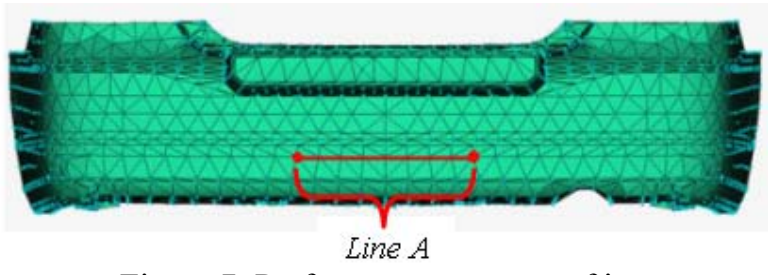

Figure 7: Performance measure of interest

\subsubsection{Optimization}

The optimization problem in this application is defined as follows:

$$
\begin{array}{lc}
\text { Find } & \mathrm{T}_{w}, \mathrm{~T}_{m}, \mathrm{I}_{\text {top }}, \mathrm{I}_{\text {bottom }}, \mathrm{I}_{\text {alternate }} \text { to } \\
\text { Minimize } & \text { Variability shrinkage } A \\
\text { Subject to } & 25^{\circ} \mathrm{C} \leq \mathrm{T}_{w} \leq 85^{\circ} \mathrm{C} \\
& 200^{\circ} \mathrm{C} \leq \mathrm{T}_{m} \leq 260^{\circ} \mathrm{C} \\
& \mathrm{I}_{\text {top }}, \mathrm{I}_{\text {bottom }}, \mathrm{I}_{\text {alternate }} \in\{0,1\} \\
& \mathrm{I}_{\text {top }}+\mathrm{I}_{\text {bottom }}+\mathrm{I}_{\text {alternate }}=1
\end{array}
$$

In optimization problem (2), the variability of shrinkage A represents the standard deviation of the estimated values of shrinkage A using the resulting nine combinations of $T_{w}$ and $T_{m}$ at each nominal set point. The first two constraints represent the experimental region of mold and melt temperature; the variables in the third row of the problem are binary, and take the value of 1 when a particular injection gates configuration is selected or 0 when it is not selected. The last constraint allows only one configuration to be chosen.

In order to solve this problem we used the SOM shown in section 2. Table 5 shows the initial DOE with a total of 15 runs. When examined carefully, this design is a Central Composite Design with only the center and axial runs on $\mathrm{T}_{w}$ and $\mathrm{T}_{m}$, repeated three times, one per configura- 
Villarreal, Mulyana, Castro, and Cabrera-Ríos

tion. Table 6 shows the SOM iterations and is organized as follows: column 1 indicates the iteration number; columns 2 and 3 show the solutions and objective function value obtained at each iteration; column 4 indicates the incumbent solution at each iteration; and the last column shows the $\mathrm{R}^{2}$ value of the metamodel.

Table 5: Initial Design of Experiments (case 1)

\begin{tabular}{|ccccc|c|}
\hline $\begin{array}{c}\mathbf{T}_{\boldsymbol{w}} \\
\left({ }^{\mathbf{9}} \mathbf{C}\right)\end{array}$ & $\begin{array}{c}\mathbf{T}_{\boldsymbol{m}} \\
\left.\mathbf{(}^{\mathbf{0}} \mathbf{C}\right)\end{array}$ & $\mathbf{I}_{\text {top }}$ & $\mathbf{I}_{\text {bottom }}$ & $\mathbf{I}_{\text {alternate }}$ & $\begin{array}{c}\text { StDev } \\
\text { Shrinkage } \\
\mathbf{A}(\mathbf{m m})\end{array}$ \\
\hline 40 & 230 & 1 & 0 & 0 & 0.4111 \\
55 & 215 & 1 & 0 & 0 & 0.4794 \\
55 & 230 & 1 & 0 & 0 & 0.4501 \\
55 & 245 & 1 & 0 & 0 & 0.2793 \\
70 & 230 & 1 & 0 & 0 & 0.2076 \\
40 & 230 & 0 & 1 & 0 & 0.1015 \\
55 & 215 & 0 & 1 & 0 & 0.0982 \\
$\mathbf{5 5}$ & $\mathbf{2 3 0}$ & $\mathbf{0}$ & $\mathbf{1}$ & $\mathbf{0}$ & $\mathbf{0 . 0 8 7 1}$ \\
55 & 245 & 0 & 1 & 0 & 0.0876 \\
70 & 230 & 0 & 1 & 0 & 0.0880 \\
40 & 230 & 0 & 0 & 1 & 0.4146 \\
55 & 215 & 0 & 0 & 1 & 0.4580 \\
55 & 230 & 0 & 0 & 1 & 0.4971 \\
55 & 245 & 0 & 0 & 1 & 0.3352 \\
70 & 230 & 0 & 0 & 1 & 0.2608 \\
\hline
\end{tabular}

Table 6: Application of the proposed method to minimize variability of Shrinkage A (case 1)

\begin{tabular}{|c|c|c|c|c|}
\hline & & & & \\
\hline $\begin{array}{c}\text { Initial } \\
\text { DOE }\end{array}$ & $(55,230,0,1,0)$ & 0.0871 & $\begin{array}{c}{[(55,230,0,1,0),} \\
0.0871]\end{array}$ & - \\
\hline $\mathbf{1}$ & $(25,260,0,1,0)$ & 0.0731 & $\begin{array}{c}{[(25,260,0,1,0),} \\
0.0731]\end{array}$ & 93.05 \\
\hline $\mathbf{2}$ & $(85,260,0,1,0)$ & 0.0874 & $\begin{array}{c}{[(25,260,0,1,0),} \\
0.0731]\end{array}$ & 94.96 \\
\hline $\mathbf{3}$ & $(85,260,1,0,0)$ & 0.0868 & $\begin{array}{c}{[(25,260,0,1,0),} \\
0.0731]\end{array}$ & 94.32 \\
\hline $\mathbf{4}$ & $(85,215,0,1,0)$ & 0.0944 & $\begin{array}{c}{[(25,260,0,1,0),} \\
0.0731]\end{array}$ & 94.32 \\
\hline $\mathbf{5}$ & $(25,240,0,1,0)$ & 0.1211 & $\begin{array}{c}{[(25,260,0,1,0),} \\
0.0731]\end{array}$ & 93.99 \\
\hline $\mathbf{6}$ & $(85,235,0,1,0)$ & 0.0987 & $\begin{array}{c}{[(25,260,0,1,0),} \\
0.0731]\end{array}$ & 93.59 \\
\hline $\mathbf{7}$ & $(85,260,1,0,0)$ & 0.0868 & $\begin{array}{c}{[(25,260,0,1,0),} \\
0.0731]\end{array}$ & 93.64 \\
\hline
\end{tabular}

The best solution found through the application of the optimization method was to inject a the bottom of the mold and set $\mathrm{T}_{w}=25^{\circ} \mathrm{C}$ and $\mathrm{T}_{m}=260^{\circ} \mathrm{C}$. The estimated standard deviation value for Line $\mathrm{A}$ is equal to $0.0731 \mathrm{~mm}$. It took
21 simulation runs to arrive to this solution. The method automatically stopped because the point obtained in iteration 7 had already been simulated.

As discussed by Villarreal and Cabrera-Ríos (2007), it has been observed that the method tends to explore the corner points of the search region in the initial iterations. This is precisely the case here, as it can be verified in Table 7. Starting the SOM with a design that covers the corners of the experimental region right from the beginning could have reduced the number of simulation runs required for convergence from the beginning (Villarreal and Cabrera-Ríos 2007). For illustration purposes, a central composite design with central and corner points (and no axial points) on $\mathrm{T}_{w}, \mathrm{~T}_{m}$, was tried. Tables 7 and 8 show the initial DOE and the SOM iterations respectively.

Table 7: Initial Design of Experiments (case 2)

\begin{tabular}{|ccccc|c|}
\hline $\begin{array}{c}\mathbf{T}_{\boldsymbol{w}} \\
\left({ }^{\mathbf{C}} \mathbf{C}\right)\end{array}$ & $\begin{array}{c}\mathbf{T}_{\boldsymbol{m}} \\
\left(\mathbf{C}^{\mathbf{0}} \mathbf{C}\right)\end{array}$ & $\mathbf{I}_{\text {top }}$ & $\mathbf{I}_{\text {bottom }}$ & $\mathbf{I}_{\text {alternate }}$ & $\begin{array}{c}\text { StDev } \\
\text { Shrinkage } \\
\mathbf{A}(\mathbf{m m})\end{array}$ \\
\hline 25 & 200 & 1 & 0 & 0 & 0.1430 \\
25 & 260 & 1 & 0 & 0 & 0.3926 \\
85 & 200 & 1 & 0 & 0 & 0.3632 \\
85 & 260 & 1 & 0 & 0 & 0.0868 \\
55 & 230 & 1 & 0 & 0 & 0.4501 \\
25 & 200 & 0 & 1 & 0 & 0.7237 \\
25 & 260 & $\mathbf{0}$ & $\mathbf{1}$ & $\mathbf{0}$ & $\mathbf{0 . 0 7 3 1}$ \\
85 & 200 & 0 & 1 & 0 & 0.1020 \\
85 & 260 & 0 & 1 & 0 & 0.0874 \\
55 & 230 & 0 & 1 & 0 & 0.0871 \\
25 & 200 & 0 & 0 & 1 & 0.1597 \\
25 & 260 & 0 & 0 & 1 & 0.4629 \\
85 & 200 & 0 & 0 & 1 & 0.4476 \\
85 & 260 & 0 & 0 & 1 & 0.0874 \\
55 & 230 & 0 & 0 & 1 & 0.4970 \\
\hline
\end{tabular}

Table 8: Application of the proposed method to minimize variability of Shrinkage A (case 2)

\begin{tabular}{|c|c|c|c|c|}
\hline & 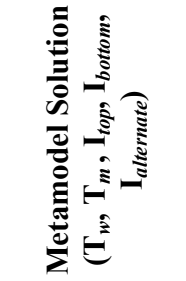 & 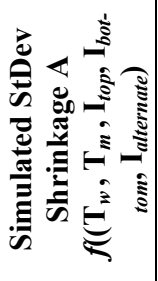 & 苨 & $\begin{array}{l}\underbrace{e} \\
\approx\end{array}$ \\
\hline $\begin{array}{l}\text { Initial } \\
\text { DOE }\end{array}$ & $(25,260,0,1,0)$ & 0.0731 & $\begin{array}{c}{[(25,260,0,1,0),} \\
0.0731]\end{array}$ & -- \\
\hline 1 & $(25,260,0,1,0)$ & 0.0731 & $\begin{array}{c}(25,260,0,1,0), \\
0.0731]\end{array}$ & 30.45 \\
\hline
\end{tabular}

The solutions obtained in both cases are the same, but in the second case the SOM required only 15 simulation runs instead of 21 . 
Further exploration on the smart use of corner points will be conducted in the future to reduce the number of simulation runs required by the SOM to converge.

Previous work in our group by Gaido (2007) reported the optimization of the this part using a multicriteria optimization method. In that case she used the same process settings with two conflicting performance measures: minimum estimated shrinkage and minimum estimated variability of shrinkage. In the optimization, the best compromises between all the performance measures based in a finite number of possible solutions were found through DEA. The resulting solutions are called efficient solutions (Charnes, Cooper, and Rhodes 1978). The efficient solutions found were $\left(\mathrm{T}_{w}, \mathrm{~T}_{m}, \mathrm{I}_{\text {top }}, \mathrm{I}_{\text {bottom }}, \mathrm{I}_{\text {alternate }}\right)=\left\{\left(25^{\circ} \mathrm{C}\right.\right.$, $\left.200^{\circ} \mathrm{C}, 1,0,0\right),\left(25^{\circ} \mathbf{C}, \mathbf{2 6 0}^{\circ} \mathbf{C}, \mathbf{0}, \mathbf{1 , ~ 0}\right),\left(25^{\circ} \mathrm{C}, 200^{\circ} \mathrm{C}, 0\right.$, $\left.0,1),\left(25^{\circ} \mathrm{C}, 230^{\circ} \mathrm{C}, 0,0,1\right)\right\}$.

We can see that one of these solutions is the same that the best solution found with the single criterion SOM. Both of these results combined support strong evidence in favor of the solution quality of the SOM, and show the consistent behavior of the algorithm initially tested in (Villarreal 2007). It is important to note that the results obtained are consistent with actual moldings.

All the simulation runs were performed using MPI 6.1, in a desktop computer with operative system Window XP Service Pack 2, processor Intel Core 2, $2.39 \mathrm{GHz}$ and $2 \mathrm{~GB}$ of RAM.

\section{CONCLUSIONS AND FUTURE WORK}

In this work, the application of a simulation optimization method was presented. The objective was to find the values of different process conditions and design parameters for the injection molding of a simple rectangular plate as well as a real automotive part. The method found an attractive solution with a modest number of simulations runs. The method can be applied to either discrete or continuous simulations .

One particularly attractive feature of the method is its transparency and its ease of being implemented with low computational resources. In fact, the analyses shown here were all carried out using the standard version of MS Excel.

Future work includes refining the method and characterizing the instances that call for more specific DOEs; as well as experiment with other different metamodels. We will also extend its use to improve the location of the efficient frontier in multicriteria optimization method as well as develop process windows for injection molding and composite manufacturing. We plan to use the method to conditions where only experimental results are available.

\section{ACKNOWLEDGMENTS}

The authors thank Honda Manufacturing of America, Marysville, Ohio and the OSU/Honda partnership for financial support of this project.

\section{REFERENCES}

Alam, K., and M. R. Kamal. 2005. A Robust Optimization of Injection Molding Runner Balancing. Computer Applications in Chemical Engineering 29(9):19341944.

Andradóttir, S. 1998. A review of Simulation Optimization techniques. In Proceedings of the 1998 Winter Simulation Conference, 151-158.

April, J., F. Glover, J. P. Kelly, and M. Laguna. 2003. Practical introduction to Simulation Optimization. In Proceedings of the 2003 Winter Simulation Conference, 71-78.

April, J., M. Better, F. Glover, and J. Kelly. 2004. New Advances and applications for marrying Simulation and Optimization. In Proceedings of the 2004 Winter Simulation Conference.

Azadivar, F. 1999. Simulation Optimization Methodologies. In Proceedings of the 1999 Winter Simulation Conference, 93-100.

Barton, R. R. 1998. Simulation Metamodels. In Proceedings of the 1998 Winter Simulation Conference, 167174.

Cabrera-Ríos, M., J. M. Castro and C. A. MountCampbell. 2002. Multiple Quality Criteria Optimization In In-Mold Coating (IMC) With A Data Envelopment Analysis Approach. Journal of Polymer Engineering 22(5):305-340.

Cabrera-Ríos, M., K. S. Zuyev, X. Chen, J. M. Castro, and E. J. Straus. 2002a. Optimizing Injection Gate Location and Cycle Time for the In-Mold Coating (IMC) Process. Polymer Composites 23(5):723-738.

Cabrera-Rios, M. 2002b. Multiple criteria optimization studies in reactive in-mold coating. $\mathrm{PhD}$ Thesis, Department of Industrial, Welding and Systems Engineering, The Ohio State University, Columbus, Ohio.

Castro, C.E. 2005. Optimization and analysis of variability in high precision injection modeling. Master Thesis, Department of Industrial, Welding and Systems Engineering, The Ohio State University, Columbus, Ohio.

Castro, C. E., M. Cabrera-Ríos, B. Lilly, and J. M. Castro. 2005. Simultaneous Optimization of Mold De-sign and Processing Conditions in Injection Molding. Journal of Polymer Engineering 25(6):459-486.

Castro, C. E., M. Cabrera-Ríos, B. Lilly and J. M. Castro. 2006. Optimization and Analysis of Variability in Injection Molding, Accepted for publication in Journal of Polymer Engineering and Science.

Castro, J. M., M. Cabrera-Ríos, and C.A. MountCampbell. 2004. Modeling and Simulation in Re- 
active Polymer Processing. Modelling and Simulation in Materials Science and Engineering 12:S121-S149.

Charnes, A., W. W. Cooper, and E. Rhodes. 1978. Measuring the efficiency of decision making units. European Journal of Operational Research 2(6):429-444.

Fu, M. C. 2001. Simulation Optimization. Proceedings of the 2001 Winter Simulation Conference: 53-61.

Fu, M. C., F. Glover and J. April. 2005. Simulation Optimization: A review, new developments, and application. In Proceedings of the 2005 Winter Simulation Conference, 83-95.

Gokce, A. K.-T. Hsiao and S. G. Advani. 2002. Branch and Bound Search to Optimize Injection Gate Locations in Liquid Composites Molding Processes. Composites Part A: Applied Science and Manufacturing 33(9): 1263-1272.

Gaido, T. 2007. Evaluation of alternative injection strategies with variability consideration in injection molding. Master Thesis, Department of Industrial, Welding and Systems Engineering, The Ohio State University, Columbus, Ohio.

Gaido, T., N. Bhagavatula, J.M. Castro, and M. Cabrera.Ríos. 2007. Evaluation of alternative injection strategies with variability consideration in injection molding. Journal of Polymer Engineering 27(8): 547.

Martin, J. D., and T. W. Simpson. 2002. Use of adaptive metamodeling for design optimization. In Proceedings 9th AIAA/ISSMO Symposium on Multidisciplinary Analysis and Optimization, 1-9.

Ólafsson, S., and J. Kim. 2002. Simulation Optimization. In Proceedings of the 2002 Winter Simulation Conference, $79-84$.

Oswald, T.A., and J. Hernandez-Ortiz. 2006. Polymer Processing: Modeling Simulation, HANSER.

Rosato, D.V., and M.G. Rosato. 1986. Injection Molding Handbook.

Smith, D. E., D. A. Tortorelli, and C. L. Tucker III. 1998. Analysis and Sensitivity Analysis for Polymer Injection and Compression Molding. Computer Methods in Applied Mechanics and Engineering 167(3-4):325344.

Swisher, J. R., P. D. Hyden, S. H. Jacobson, and L. E. Schruben. 2000. A survey of simulation optimization techniques and procedures. In Proceedings of the 2000 Winter Simulation Conference, 119-128.

Villarreal, M.G., and Cabrera-Ríos, M. 2007. Un método adaptativo basado en metamodelos para optimización aplicada a la simulación. In Proceedings of the IEEE $5^{\circ}$ International Conference in Innovation and Technological Development.

Villarreal, M.G. 2007. Modelación y Optimización Aplicada a la Simulación de Procesos y Sistemas de Manufactura. Master Thesis, Department of Systems Engineering, Universidad Autónoma de Nuevo León, Nuevo León, México.

Zhou, J., and L.S. Turng. 2007. Process optimization of in- jection molding using an adaptative surrogate model with gaussian process apptoach. Polymer Engineering and Science, 684-694.

\section{AUTHOR BIOGRAPHIES}

MARÍA GUADALUPE VILLARREAL MARROQUÍN is visiting scholar at The Ohio State University. She obtained her B.S. in Mathematics(2005) and M.S. in Systems Engineering(2007) from Universidad Autónoma de Nuevo León, México. Her interests include Simulation Optimization, Operations Research and Applied Mathematics.

<villarreal.28@osu.edu>.

RACHMAT MULYANA is currently working on his $\mathrm{PhD}$ at the Ohio State University majoring in Industrial and Systems Engineering. After obtaining his Bachelor in Chemical Engineering, he worked at the Scotts Company for 2 years as Pilot Plant associate engineer. Master degree in Industrial Engineering was obtained in 2006 with research in polymer processing, simulation works and optimization. <mulyana.1@osu.edu>.

JOSE M CASTRO is currently professor and graduate studies chair in the department of Industrial, Welding, and Systems Engineering and co-director of the Center for Advanced Polymers and Composites Engineering at The Ohio State University. After obtaining his PhD in Chemical Engineering from the University of Minnesota in 1980, he was a faculty at the chemical engineering department of the University of the South in Bahia Blanca Argentina for four years. He then worked at the Gen Corp corporate technology center for 12 years in automotive composites where he was a chief technologist. After GenCorp he worked for three years as Manager of the New Process technology group in Allied Signal Electronic Materials. He joined Ohio State in September 1998. He has published more than 60 peer review journal papers and given numerous invited talks. His area of research is polymer processing and composites manufacturing modeling and optimization. <castro.38cosu.edu> .

MAURICIO CABRERA RÍOS obtained his B.S. in Industrial and Systems Engineering from ITESM-Monterrey (1996), and his M.S. and Ph.D. in the same discipline from The Ohio State University $(1999,2002)$. He is an Assistant Professor at the Industrial Engineering Department at University of Puerto Rico-Mayagüez.

$<$ mcabrera@uprm. edu>. 